\title{
THE CYCLICAL COMPONENT IN BRAZILIAN GDP*
}

\author{
Francisco Cribari-Neto**
}

\section{Resumo}

O presente artigo apresenta uma estimativa da componente cíclica do PIB brasileiro que permite que a tendência siga um processo estocástico. Esta estimativa é comparada a uma estimativa "ingênua" que impõe uma estrutura determinística à tendência do PIB. O principal resultado contido neste artigo é que a componente cíclica do PIB brasileiro é muito pequena e portanto quase todas as flutuaçães do produto têm sido causadas por fatores de longo prazo, i.e., fatores reais.

\section{Abstract}

This paper presents an estimate of the cyclical component in Brazilian GDP obtained by allowing the trend component to follow a stochastic process. It also compares this estimate with a more naive one, obtained by forcing the trend to be deterministic. The main result this paper conveys is that the cyclical component in Brazilian GDP is very small, and hence almost all output fluctuations have been caused by long-run (real) factors.

\section{Int roduction.}

How large is the cyclical component in Brazilian GDP? This is an important question with strong policy implications. Stabilization policies are designed to stabilize cyclical fluctuations, and hence it is important to know to what extent this kind of oscillation occurs. In the extreme case that they do not exist at all, these policies are bound to be ineffective and the government should concentrate its efforts on long-run policies. On the other hand, if business cycles

\footnotetext{
*I would like to thank Anne Villamil, Kenneth Brown and two anonymous referees for helpful comments. I have also benefited from conversations with John Cochrane and Paul Newbold. The financial support of CNPq/Brazil is gratefully acknowl edged.

** From the Ph.D. program in economics at the University of Illinois. Correspondence to: Francisco Cribari-Neto, Department of Economics, University of Illinois, 484 Commerce West, 1206 South Sixth Street, Champaign IL, 61820, USA (e- mail: cribari@uxh.cso.uiuc.edu).
}

\begin{tabular}{llll}
\hline R. de Econometria Rio de Janeiro & v. $13, \mathrm{n}$ 으 1, pp.1-22 & . abril 1993
\end{tabular}


account for most fluctuations in GDP, one can forcefully argue in favor of implementation of short-run policies.

This paper represents an attempt to provide the question posed above with an answer. I consider two different strategies to estimate the cyclical component. The first one, which I call deterministic trend. decomposition (DTD), consists of attributing all oscillations around a deterministic trend to that component. This is the traditional approach, largely employed in the literature until the late 1970s. The second procedure is known as the Beveridge-Nelson decomposition, and I shall call it stochastic trend decomposition (STD) henceforth. It assumes that the trend component follows a drifted random walk process and that innovations in both components are perfectly correlated. It should be said that there are other univariate decompositions based on stochastic trends such as the so-called "structural models" (Harvey, 1985). I chose not to use such models because they restrict the degree of persistence of innovations a priori to the interval $[0,1)$ as shown by Lippi and Reichlin $(1992)^{1}$ and because they restrict the class of ARIMA models and their respective parameter spaces again on an entirely a priori basis (Newbold, 1991). Furthermore, these models may spuriously overstate the size of the cyclical component as shown by Nelson (1987). ${ }^{2}$

It has been argued that the DTD is somewhat naive in the sense that it does not allow for random movements in the trend component, forcing the long-run trend to be deterministic. In an influential paper, Nelson and Plosser (1982) have shown that this is not consistent with most macroeconomic time series, since it is not possible to reject the null hypothesis of a unit autoregressive root in their representation which implies the presence of a stochastic trend. Moreover, this procedure introduces several spurious patterns in the detrended series when the trend evolves stochastically (Nelson and Kang, 1984). An important spurious effect is that when a series that follows a ran-

\footnotetext{
${ }^{1}$ They have shown that a measure of persistence of shocks less than one is a mathematical consequen ce of these models. See also Cribari-Neto (1993).

${ }^{2}$ Another possibility would be to consider piecewise stationary models (Perron, 1989), as suggested by a referee. Nevertheless, the data used in this paper do not display any visible break point in the trend. For a criticism of this approach, see Cribari-Neto (1993).
} 
dom walk is detrended it will display a pseudo-periodicity (Nelson and Kang, 1981). ${ }^{3}$ It can then be seen that this approach tends to overstate the importance of business cycles in output fluctuations.

The STD is more realistic in the sense that it does allow the trend component to be affected by random shocks. In particular, it assumes that this component evolves according to a random walk with constant drift. Intuitively, one should expect the trend to follow a stochastic process since consumption, the largest component of GDP, follows a random walk (Hall, 1978) or a process close to a random walk. ${ }^{4}$ Indeed, consumption provides a good estimate of the trend in GDP (Cochrane, 1992).

The main result this paper conveys is that, when the trend is allowed to evolve stochastically, the cyclical component becomes very small, almost non-existent. This result suggests that almost all fluctuations in Brazilian GDP have been caused by real factors, such as population growth, capital accumulation and technological innovations. It also has the strong policy implication that short-run policies designed to stabilize recessions can never be successful. ${ }^{5}$ It is important to remark, though, that this does not mean that economic policies are not able to reduce persistent effects of economic shocks. ${ }^{6}$ In a broader context, my findings support the so-called "real business cycles models", which attribute short-run fluctuations to longrun (real) factors. These models place more emphasis than did the previous equilibrium-approach literature on the propagation of shocks and emphasize real - as opposed to monetary - disturbances as the source of cyclical fluctuations (McCallum, 1989). ${ }^{7}$ A striking feature

\footnotetext{
${ }^{3}$ See also Cribari-Neto (1989).

4 John Cochrane brought this point to my attention.

${ }^{5}$ It should be remarked that even if one assumes that su ch poli cies can achieve their goals, it is not clear that they will lead to substantial improvements in welfare. For instance, in the second chapter of his Models of Business Cycles Lucas (1987) shows that the welfare gains of eliminating aggregate consumption variability are very small. Indeed, they are equivalent (in utility terms) to an increase in average consumption of less than 0.1 percent (pp.26-27).

${ }^{6}$ The results in Cribari-Neto (1992a), for example, suggest that the policies introduced in Brazil after the first international oil shock were successful in reducing the long-run effects of this innovation.

${ }^{7}$ For a good intro duction to these models, see Plosser (1989).
} 
of the real business cycles models is that they deal with short-run and long-run fluctuations in a unified framework, i.e., they account for fluctuations at all frequencies by the same shock, and hence there is no meaningful distinction between the short-run and the long-run (Shapiro and Watson, 1988, p.112).

The rest of the paper is organized as follows. The next section briefly reviews the estimation methodology. In Section 3, I present the results. Section 4 includes some further results and the last section concludes the paper.

\section{Deterministic and stochastic trend decompositions.}

Let $y_{t}$ denote the natural logarithm of real GDP. The goal here is to decompose this time series into a trend $\left(y_{t}^{t}\right)$ and a cyclical $\left(y_{t}^{c}\right)$ component such that $y_{t}=y_{t}^{t}+y_{t}^{c}$. The DTD assumes that $y_{t}^{t}$ is a linear function of time and thus $y_{t}^{c}$ is obtained as $y_{t}-\hat{\beta}_{0}-\hat{\beta}_{1} t$, where $t$ is a time index and $\hat{\beta}^{\prime}=\left(\hat{\beta}_{0}, \hat{\beta}_{1}\right)$ is the ordinary least squares (OLS) estimate of $\beta^{\prime}$.

The STD is less straightforward. Let $w_{t}$ represent the first difference of $y_{t}$. If $y_{t}$ is integrated of first order this series is stationary and its Wold representation is given by

$$
w_{t}=\mu+\sum_{j=0}^{\infty} \lambda_{j} \varepsilon_{t-j}, \quad \lambda_{0} \equiv 1 .
$$

Here, $\mu$ is a constant (the long-run growth rate) and $\varepsilon_{t}$ is an independent and identically distributed disturbance term. Given this setup and assuming that innovations in both components of GDP are perfectly correlated, the trend component is given by

$$
y_{t}^{t}=y_{t}+\sum_{j=0}^{\infty}\left(\sum_{i=j+1}^{\infty} \lambda_{i}\right) \varepsilon_{t-j}
$$

or by

$$
y_{t}^{t}=y_{t}+\lim _{h \rightarrow \infty}\left(\sum_{j=1}^{h} \check{w}_{t}(j)-h \mu\right) \text {, }
$$


where $\check{w}_{t}(j)$ is the conditional expectation of $w_{t+j}$ held at time $t$. The second term on the right hand side of $(2 \mathrm{~b})$ represents the sum of all forecasted movements in the series apart the drift. It can easily be shown using (1) and (2a) that $y_{t}^{t}$ follows a random walk with drift $\mu$ and with an innovation which is proportional to the innovation in the original series. (The variance of the innovation in the trend component may be smaller, equal or greater than the variance of the innovation in the original series.) The cyclical component is then given by

$$
-y_{t}^{c}=\sum_{j=0}^{\infty}\left(\sum_{i=j+1}^{\infty} \lambda_{i}\right) \varepsilon_{t-j}
$$

or by

$$
-y_{t}^{c}=\lim _{h \rightarrow \infty}\left(\sum_{j=1}^{h} \check{w}_{t}(j)-h \mu\right) .
$$

That is, the cyclical component in (3) is "a stationary process which represents the forecastable momentum present at each period but which is expected to be dissipated as the series tends to its permanent level" (Beveridge and Nelson, 1981, p.158). It should be noted that there are no business cycles when $y_{t}$, the series in levels, follows a drifted random walk.

It is noteworthy that the additive structure is assumed for the logarithm of GDP $\left(y_{t}\right)$, and not for the original series $\left(\exp \left(y_{t}\right)\right)$ as some authors have mistakenly assumed (e.g., Cuddington and Urzúa, 1989, p.330).

There are several different ways to estimate the cyclical component given in (3). Newbold (1990) has recently proposed a precise method for the computation of this component. His method is preferable to the methods proposed by Cuddington and Winters (1987) and Miller (1988) because it does not require any truncation. Let $w_{t}^{+}=w_{t}-\mu$ be represented by the $\operatorname{ARMA}(p, q)$ model

$$
\phi(B) w_{t}^{+}=\theta(B) \varepsilon_{t}
$$


where $B$ is the backshift operator and the roots of $\phi(B)$ and $\theta(B)$ lie outside the unit circle. Then, Newbold (1990) has shown that

$$
-y_{t}^{c}=\sum_{j=1}^{q} \check{w}_{t}^{+}(j)+\left(1-\sum_{j=1}^{p} \phi_{j}\right)^{-1} \sum_{j=1}^{p} \sum_{i=j}^{p} \phi_{i} \check{w}_{t}^{+}(q-j+1) .
$$

When required, the kth step-ahead forecast of $\check{w}_{t}^{+}$can be computed via the Kalman filter.

\section{Two estimates of the cyclical component.}

This section presents two different estimates of the cyclical component. The first is based on a deterministic trend decomposition whereas the second is based on a stochastic trend decomposition. The data for the estimations consist of the index of the natural logarithm of Brazilian real GDP $\left(y_{t}\right)$ from 1900 to 1990. Estimates for the period 1900/1947 were taken from Haddad (1977). A graphical presentation of the data is given in Figure 1.

Table 1.

Unit Root Tests

\begin{tabular}{ccccc}
\hline lags & $t_{\hat{\alpha}_{*}}$ & $t_{\tilde{\alpha}_{*}}$ & $Z\left(t_{\hat{\alpha}}\right)$ & $Z\left(t_{\bar{\alpha}}\right)$ \\
\hline 1 & 0.884 & -2.084 & 0.717 & -1.766 \\
2 & 0.815 & -2.329 & 0.689 & -1.797 \\
3 & 0.600 & -2.158 & 0.675 & -1.814 \\
4 & 0.665 & -1.852 & 0.685 & -1.803 \\
6 & 0.369 & -2.048 & 0.680 & -1.811 \\
8 & 0.144 & -1.655 & 0.678 & -1.813 \\
10 & 0.400 & -2.273 & 0.687 & -1.802 \\
12 & 0.227 & -2.150 & 0.687 & -1.799 \\
\hline
\end{tabular}

At the beginning, it is important to know whether the trend in $y_{t}$ is stochastic or deterministic. As is well know, the hypothesis that the nature of the trend is stochastic can be tested by testing the null 
Cribari-Neto

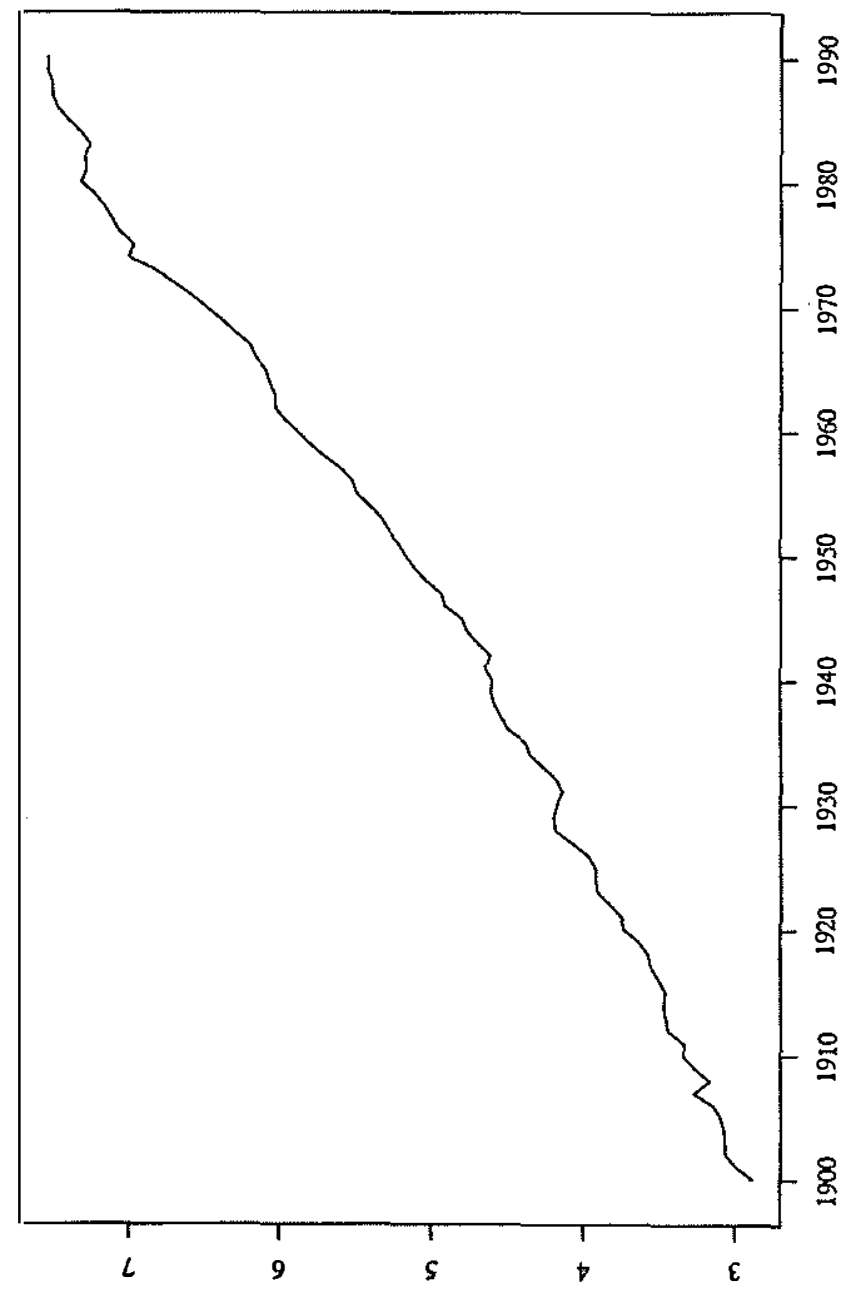

Figure 1.

Log of Brazilian GDP - 1900/1990

Revista de Econometria 13(1) abril 1993 
hypothesis that the series has a unit autoregressive root (Nelson and Plosser, 1982). To this end, I carried out two different tests. The first test is known as the augmented Dickey-Fuller test (ADF) and is based on the statistics $t_{\bar{\alpha}_{*}}$ and $t_{\bar{\alpha}_{*}}$. This test is due to Dickey and Fuller (1979); see also Said and Dickey (1984). The second is the corresponding Plillips-Perron test (PP), which is based on the test statistics $Z\left(t_{\bar{\alpha}}\right)$ and $Z\left(t_{\bar{\alpha}}\right)$. It is due to Phillips and Perron (1988); see also Perron (1988) and Phillips (1987). The latter allows for a more general structure for the error term. The results for different number of lags are given in Table 1 . The critical values for both tests are given by Fuller (1976, p.373). It is then clear that, in all cases, it is not possible to reject the null of a unit root even at the level of $10 \%$. This represents strong evidence that there is a unit autoregressive root in the representation of $y_{t}$, and hence this series has a stochastic trend.

The next step is to obtain an estimate of the cycles in GDP from a DTD. This is done by running an OLS regression of $y_{t}$ on $t=$ $1900,1901, \ldots, 1990$. As discussed in the Introduction, this is a naive estimate of the size of the business cycle. It is also an inappropriate estimate since, as shown above, the nature of the trend in GDP is not deterministic. However, it is interesting to perform this estimation for purposes of comparison with a more reliable estimate that will be presented later. The estimate of the cyclical component based on a DTD is presented in Figure 2.

This estimate seems to suggests the presence of a large cyclical component and it could lead one to believe in the presence of a cycle even longer than the Kondratieff cycle, i.e., a long wave that lasts from fourty-eight to sixty years. However, as argued above, this is not a reliable result and no inference should be based on it. The point in presenting this result is to show that inappropriate detrending procedures oftentimes overstate the dimension of the (estimated) business cycle, leading one to argue in favor of countercyclical policies which are indeed inadequate.

The next step is to find an estimate for the business cycle based on a STD using the methodology discussed in the previous section. At the outset, it is necessary to choose an $\operatorname{ARMA}(p, q)$ model that approximates $w_{t}^{+}$. To this end, it is necessary to estimate several 
Cribari-Neto

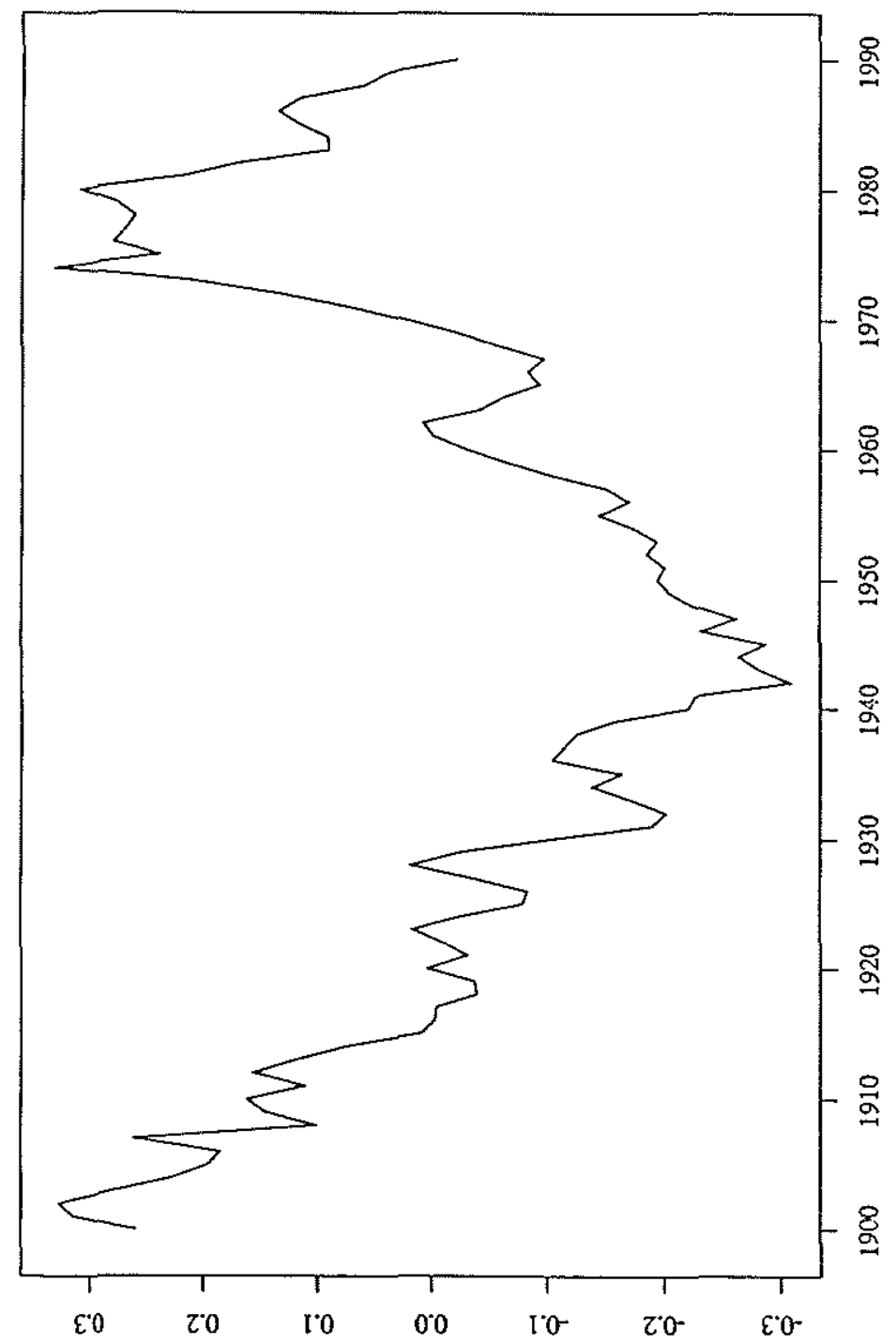

Figure 2.

Cycles based on a DT decomposition 
different models and choose the one that minimizes a certain model selection criterion. The criterion used for this selection was Hurvich and Tsai's (1989) AICC. This criterion is a bias-corrected version of the AIC, and is known to perform well in small samples. It is given by

$$
\mathrm{AICC}=-2 \ln L+\frac{2 T(p+q+1)}{T-p-q-2},
$$

where $L$ is the likelihood of the data under the Gaussian ARMA representation and $T$ is the number of observations. This criterion incorporates a small sample correction to offset the well known tendency of the AIC to overfit. It should also be remarked that order selection by minimization of the AICC is asymptotically efficient for autoregressive models whereas order selection by minimization of the well known BIC is not (Brockwell and Davis, 1991, chapter 9). ${ }^{8}$ Table 2 shows the values of the AICC for different ARMA models estimated by maximum likelihood. ${ }^{9}$

The figures in Table 2 show that the AICC is minimized for the $\operatorname{ARMA}(1,0)$ model. Moreover, the FPE criterion is also minimized for this model among the autoregressive ones. The estimated model is

$$
(1-0.0653 B) w_{t}^{+}=\varepsilon_{t},
$$

with $Q(20)=9.09$ and $Q^{+}(20)=10.60$, where $Q(\cdot)$ is the usual Ljung-Box statistic and $Q^{+}(\cdot)$ is the statistic for the test of no serial correlation in the squared residuals, as proposed by McLeod and $\mathrm{Li}$ (1983). (The adequacy of this model is also accepted based on three other tests, namely: the turning points, difference-sign and rank tests.) At the outset, note that this model is very close to a random walk since $\hat{\phi}_{1}$ is close to zero and the univariate degree of persistence of innovations in long-run GDP measured by the sum of coefficients

\footnotetext{
${ }^{8}$ It is also important to remark that the AICC outperforms the AIC in the underfitting case, i.e., when none of the can didate models includes the true model. In this case, the bias of the AICC is in general smaller than that of the AIC. See Hurvich and Tsai (1991) for further details.

${ }^{9}$ The simulation results in Ansley and Newbold (1980) suggest that this method is preferable to methods based on least squares estimation.
} 
Cribari-Neto

Table 2.

Model selection based on the AICC criterion

\begin{tabular}{|c|c|}
\hline $\operatorname{ARMA}(p, q)$ & $\mathrm{AICC}$ \\
\hline$(1,0)$ & -295.0686 \\
\hline$(2,0)$ & -293.8863 \\
\hline$(3,0)$ & -291.7030 \\
\hline$(4,0)$ & -291.3599 \\
\hline$(0,1)$ & -295.0031 \\
\hline$(1,1)$ & -293.3409 \\
\hline$(2,1)$ & -291.6642 \\
\hline$(3,1)$ & -290.0574 \\
\hline$(4,1)$ & -289.3604 \\
\hline$(0,2)$ & -294.2847 \\
\hline$(1,2)$ & -292.1033 \\
\hline$(2,2)$ & -293.7426 \\
\hline$(3,2)$ & -292.0315 \\
\hline$(4,2)$ & -289.5273 \\
\hline$(0,3)$ & -292.1252 \\
\hline$(1,3)$ & -290.6277 \\
\hline$(2,3)$ & -291.7445 \\
\hline$(3,3)$ & -289.5591 \\
\hline$(4,3)$ & -287.2033 \\
\hline$(0,4)$ & -292.4046 \\
\hline$(1,4)$ & -290.1188 \\
\hline$(2,4)$ & -289.5546 \\
\hline$(3,4)$ & -287.1491 \\
\hline$(4,4)$ & -284.5493 \\
\hline
\end{tabular}

${ }^{10}$ For the model with the second smallest AICC, the $\operatorname{ARMA}(0,1)$ model, one obtains $\hat{A}(1)=1.054$. 
The cyclical component

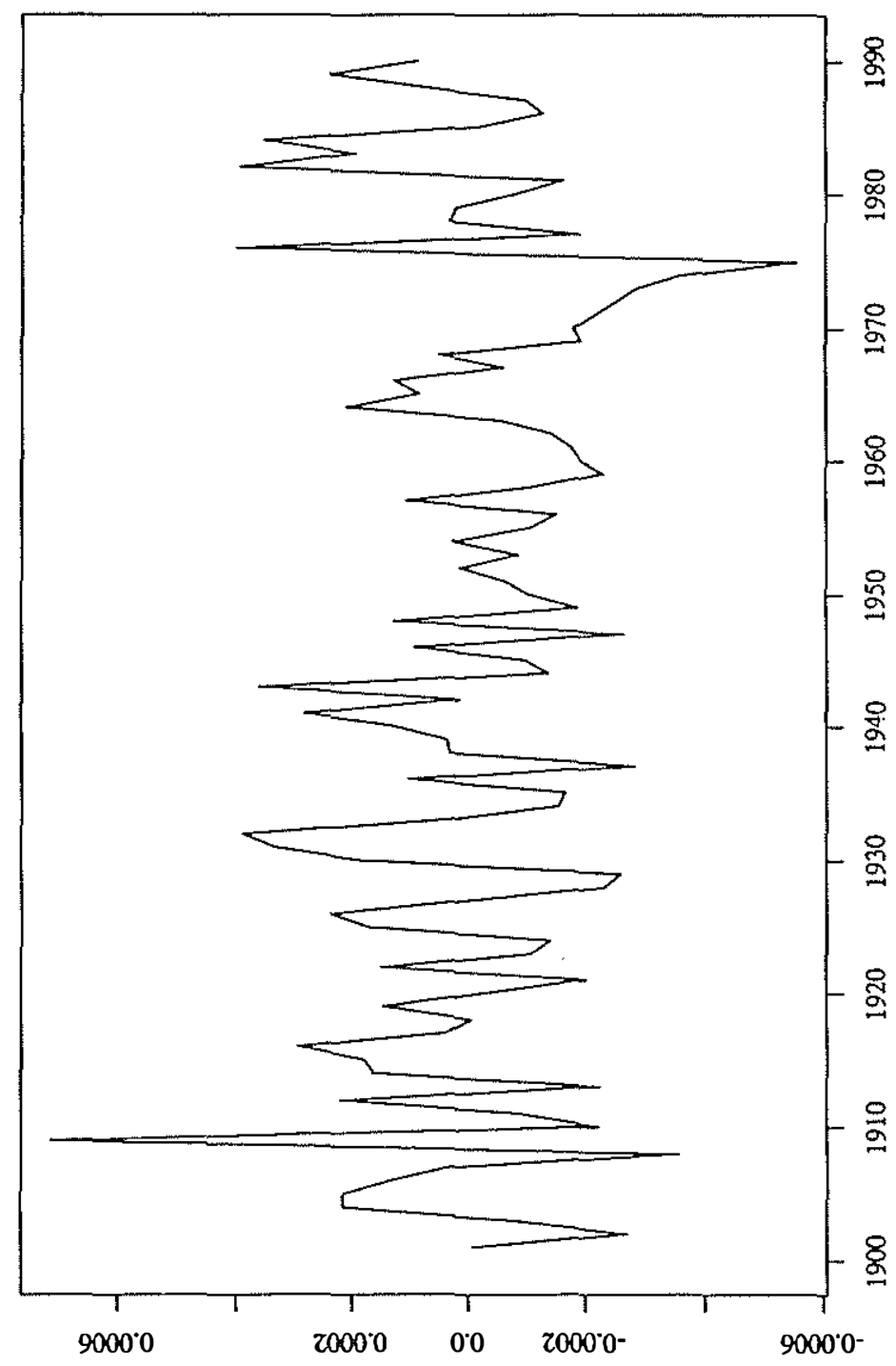

Figure 3.

Cycles based on a ST decomposition 
in the MA infinity representation $(\hat{A}(1))$ is $1.070 .{ }^{10}$ (This measure is often referred to as the cumulative impulse response function and was proposed in this context by Campbell and Mankiw (1987).) This value is close to one, the expected value for a random walk process, and somewhat smaller than other estimates available in the literature for the Brazilian case using a non-parametric approach and different sample sizes, as in Cribari-Neto (1990, 1992a). Since the selected model is very close to a random walk, one can expect the cyclical component to be small.

In order to find an estimate of the cyclical component based on the STD, I used Newbold's (1990) result. This estimate is displayed in Figure 3. It seems to be somewhat erratic and its order of magnitude reveals that it is almost null. This can be noted when both estimates (i.e., the one based on the DTD and the one based on the STD) are plotted on the same graph, as in Figure 4.

When both estimates are compared, it becomes clear that the business cycle component in Brazilian GDP in the presence of a stochastic trend is almost non-existent, that is, it is arbitrarily close to zero. The variance of the cyclical component in the DTD is 0.0290 whereas the variance of this component in the STD is only $4.391 \times 10^{-8}$, that is, this value is over 500,000 bigger under the DTD than under the STD. As pointed out before, this was expected since the decomposition is based on an ARIMA model which is very close to a random walk.

This result leads to the conclusion that almost all movements in Brazilian GDP have been caused by long-term factors, and hence there is almost no room for short-run stabilization policies.

It is also interesting to compare the two estimates of the trend component. This is done in Figure 5. This comparison shows that the stochastic trend is much more volatile than the fixed, deterministic one. Indeed, since the cyclical component is almost non-existent, the stochastic trend and the series with the raw data superimpose when plotted together.

\section{Some further results.}

\subsection{Evidence of the random walk hypothesis.}

The result presented above that the trend component accounts 
The cyclical component

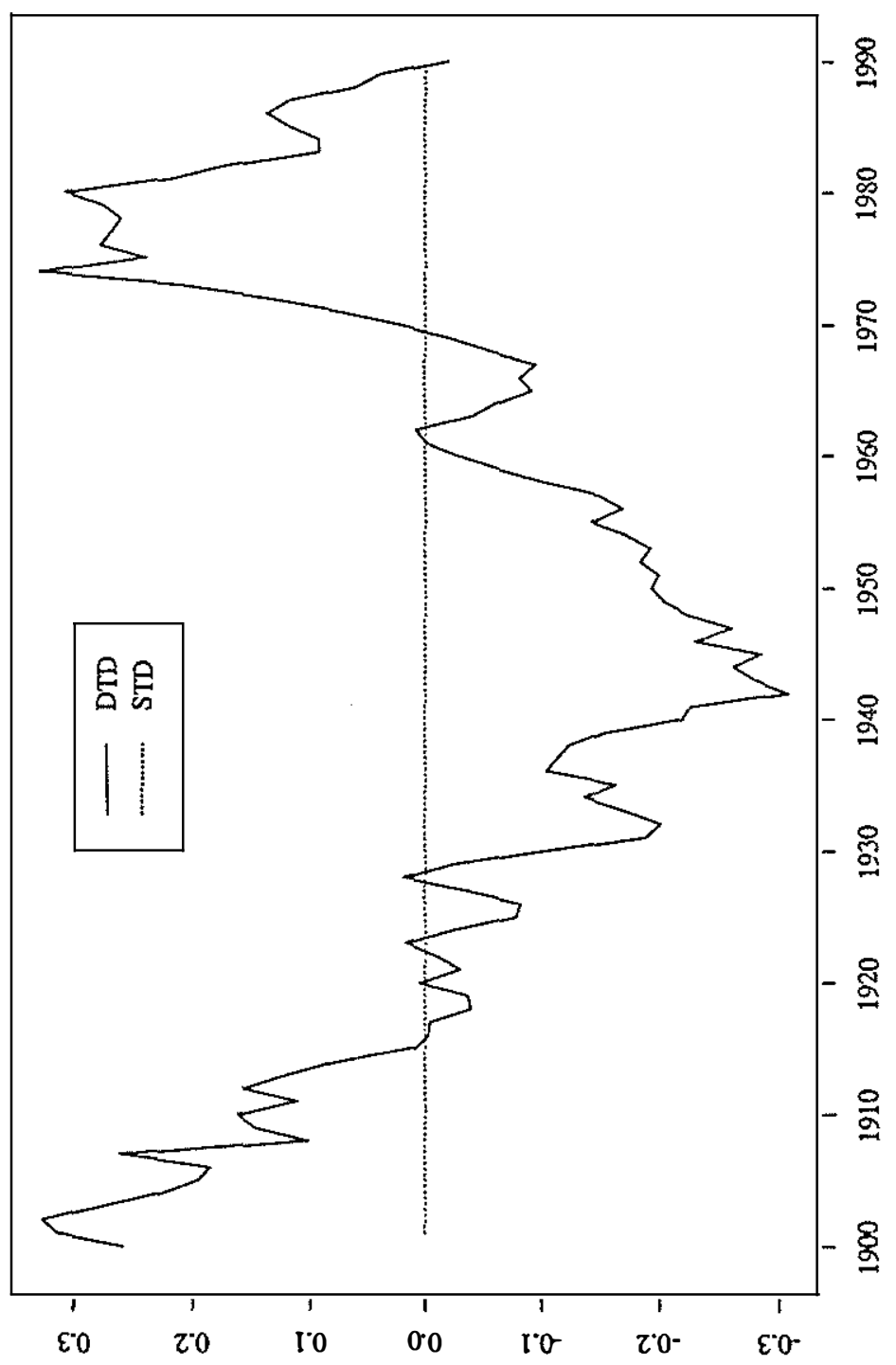

Figure 4.

Cycles - DTD and STD 
Cribari-Neto

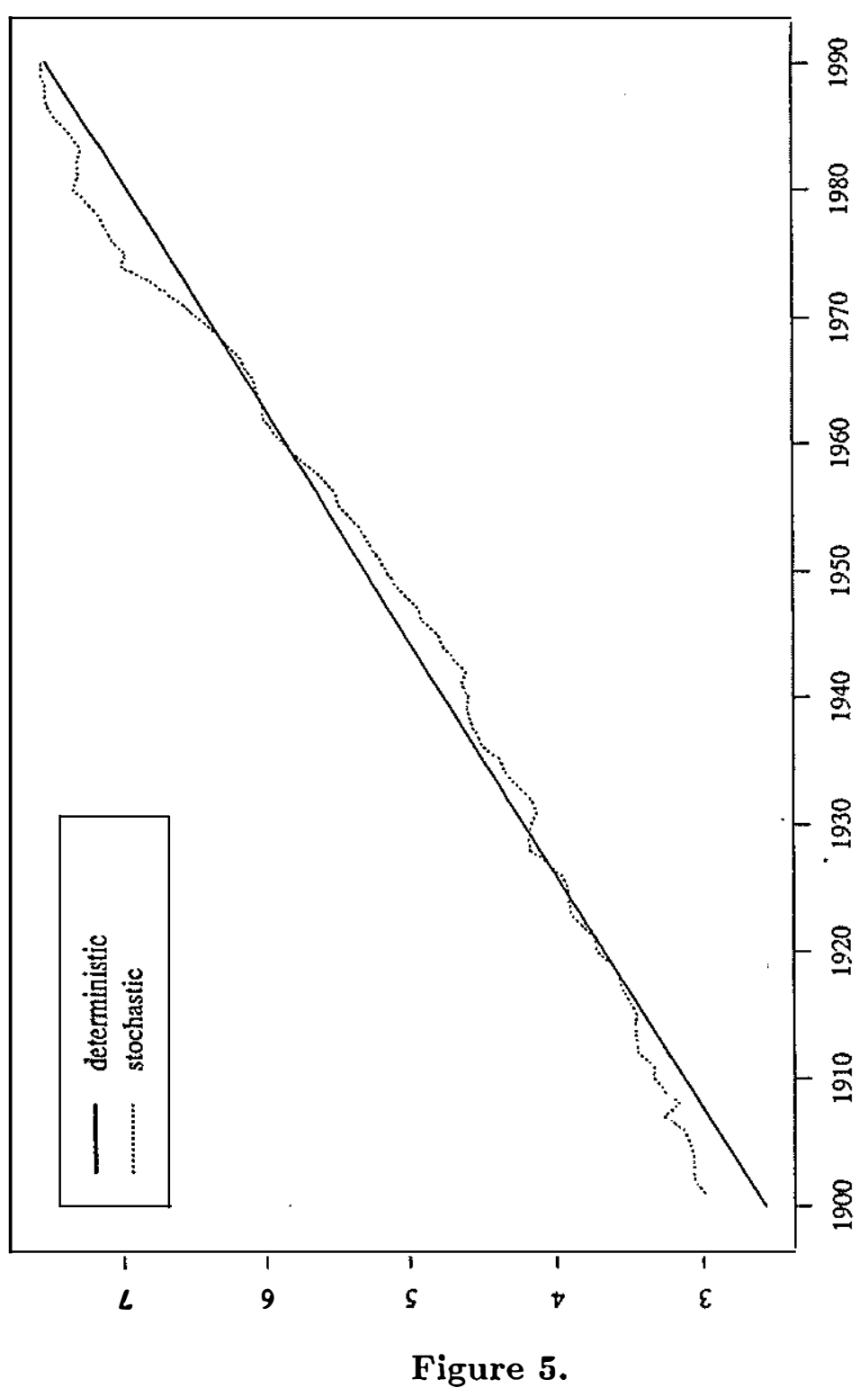

Deterministic and stochastic trends 
for almost all fluctuations in GDP can be explained as follows. As mentioned earlier, the selected model is very close to a random walk process. In addition, there is some evidence that it is not possible to reject the hypothesis that $y_{t}$ itself follows a drifted random walk. ${ }^{11}$ First, all sample autocorrelations and sample partial autocorrelations of $w_{t}$ are contained in a Bartlett-confidence interval around zero at the $5 \%$ level, i.e., they are not (individually) significantly different from zero. Second, for the first difference of the series $Q(20)=8.35$, where again $Q(\cdot)$ is the Ljung-Box statistic. The portmanteau test that the first twenty autocorrelations are jointly equal to zero has a $p$-value of 0.9893 ; that is, it is not possible to reject the null hypothesis even at extremely large significance levels. Finally, Fisher's statistic for the test of the hypothesis that the first difference of $y_{t}$ is a Gaussian white noise is 3.048 with a $p$-value of 0.0941 ; that is, it not possible to reject a (Gaussian) random walk in $y_{t}$ at the $5 \%$ level, although it is possible to reject this hypothesis at the $10 \%$ level. ${ }^{12}$ These results taken together constitute evidence that $y_{t}$ may evolve as a random walk with drift in which case the cyclical component would be identically equal to zero.

\subsection{Evidence from a bivariate approach.}

The analysis presented above takes place in a univariate framework. However, Cochrane (1992) argued that this question should also be analyzed in a bivariate context. His argument is that a shock to GDP holding consumption fixed is almost entirely transitory, and hence the persistence of innovations arises from shocks to consumption which are highly persistent. In this setting, the lagged ratio of consumption to GDP should have a large predictive power in forecasting changes in GDP leading then to the conclusion that "there is a business cycle to study after all" (p.20). In order to see whether this argument holds for the Brazilian economy, I ran a regression of the changes in GDP on a constant and the ratio of consumption to

\footnotetext{
${ }^{11}$ See Cribari-Neto (1992b) for more details on the tests used here.

${ }^{2}$ Fisher's test is very useful because it does not re ly upon asymptotic approximations and because it allows one to test for the presence of hidden periodicities with unspecified frequency.
} 
GDP lagged by one period. ${ }^{13}$ The resulting estimated regression was

$$
w_{t}=-0.1279+0.2686 c r_{t-1}
$$

where $c r$ is the ratio of total consumption by household's to GDP. For this regression, $R^{2}=0.0556, D W=1.59$ and $L M=1.74$, where $L M$ is the Lagrange multiplier statistic for the test of first-order autocorrelation. What is important to mention here is that the $t$ statistic for the test that the coefficient on $\mathrm{cr}$ is zero is 1.55 ; that is, it is not possible to reject the hypothesis that this variable has no predictive power on the changes in GDP at the $10 \%$ significance level. This finding leads to the conclusion that the results obtained in this paper are not weakened in a bivariate framework.

\subsection{An estimate of the density of the growth rate in GDP.}

All results reported above suggest that the drifted random walk model is a very good approximation to the data generating process of Brazilian GDP. Since $y_{t}$ is in logs its first difference $\left(w_{t}\right)$ can be interpreted as a very close approximation to the growth rate in the series between consecutive periods. That is, (growth rate) $t=\mu+\varepsilon_{t}$, where $\mu$, the location parameter, can be viewed as the "long-run growth rate". The goal here is to obtain some information about the behavior of the growth rate in GDP. As a first step, it is interesting to look at some descriptive statistics relating to this variable. Its mean is $5.16 \%$, the standard deviation is $4.63 \%$ and the standardized measure of kurtosis is 0.415 . That is, on average the Brazilian economy has been growing at the rate of $5.16 \%$ per year. It is also interesting to obtain an estimate of its density. To this end, I have used the logspline method, as described in Kooperberg and Stone $(1991,1992)$. This method uses maximum likelihood estimation to estimate the logarithm of the true density by a function from a space of cubic splines that have a finite number of prespecified knots and are linear in the tails. The estimated density is given in Figure 6 together with the density of a normal random variable.

\footnotetext{
${ }^{13}$ Here, I have considered the period from 1947 to 1990 . The data were obtained from the book Estatísticas Históricas do Brasil, published by the Fundação Instituto Brasileiro de Geografia e Estatística, and from Conjuntura Econômica.
} 
The cyclical component

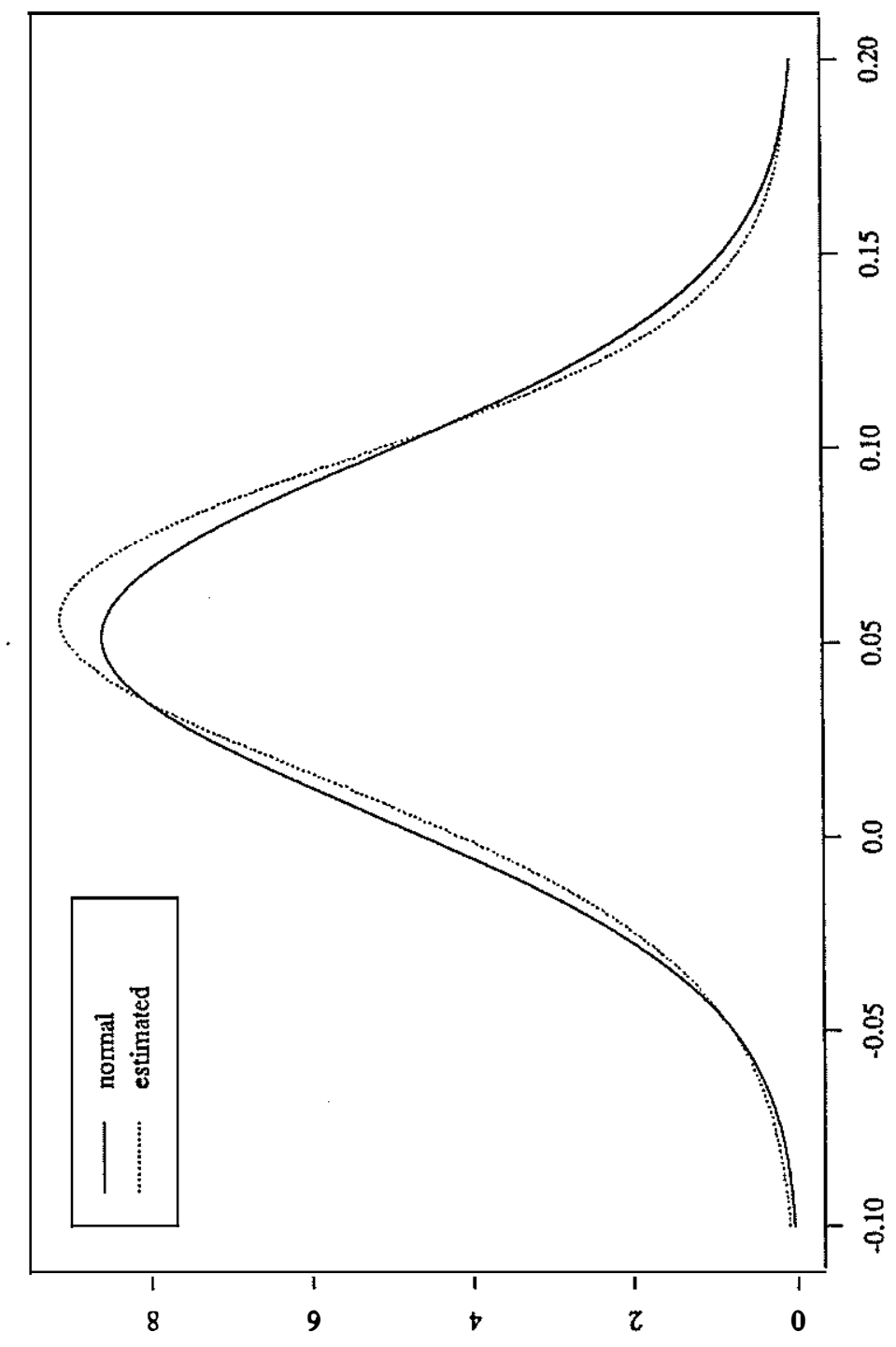

Figure 6.

Estimated density of the growth rate 
This estimate suggests that the density of the growth rate in GDP is close to a normal distribution, although it is slightly skewed to the left. Therefore, a model like $y_{t}=0.052+y_{t-1}+\varepsilon_{t}$ seems to characterize the dynamic behavior of Brazilian GDP very well. As a consequence, the cyclical component is identically equal to zero and all movements in GNP are driven by innovations in the trend.

\section{Concluding remarks.}

This paper's aim was to provide an estimate for the size of the business cycle in Brazilian GDP for the period from 1900 to 1990. It was shown that this component is arbitrarily small when one allows the trend in GDP to evolve stochastically according to a drifted random walk process. It is also shown that a "naive" estimate of the cyclical component obtained by imposing a deterministic structure to the permanent component of GDP would lead one to erroneously believe that business cycles have been responsible for a large amount of the variance in GDP over the years. The result conveyed in this paper has strong policy implications. Since short-term stabilization policies are designed to neutralize the effects of transitory disturbances caused mainly by monetary factors and real factors have accounted for almost all oscillations in GDP, stabilization policies are bound to be ineffective. Thus, an attempt to stabilize recessions and reduce temporary unemployment just adds more noise to the economy. This suggests that the government should concentrate its efforts on long-term (growth) policies. Finally, the closing of this paper should come with a word of caution. The results presented here are strong and have important policy implications. However, they are subject to the usual limitations of any parametric approach. Therefore, it is important that future research continue to analyze the issues raised in this paper.

Received October 1992. Revised January 1993.

\section{References}

Ansley, C.F. \& Newbold, P. 1980. "Finite sample properties of estimators for autoregressive moving average models." Journal of 
Econometrics 13: 159-183.

Beveridge, S. \& Nelson, C.R. 1981. "A new approach to the decomposition of time series into permanent and transitory components with particular attention to measurement of the business cycle." Journal of Monetary Economics 7:151-174.

Brockwell, P.J. \& Davis, R.A. 1991. Time Series: Theory and Methods, 2nd ed. New York: Springer-Verlag.

Campbell, J.Y \& Mankiw, N.G. 1987. "Are output fluctuations transitory?" Quarterly Journal of Economics 102: 857-880.

Cochrane, J. 1992. "Permanent and transitory components of GNP and stock prices." Mimeo, Department of Economics, University of Chicago.

Cribari-Neto, F. 1989. "A teoria da renda permanente e os movimentos estocásticos do consumo." Revista de Econometria 9:183210 .

1990. "O comportamento estocástico do produto no Brasil." Pesquisa e Planejamento Econômico 20: 381-402.

1992a. "Persistência de inovações e política econômica: a experiência do II PND." Revista Brasileira de Economia 46: $413-428$.

1992b. "A natureza estocástica do crescimento econômico canadense." Revista Brasileira de Economia 46:535-554. 1993. "Unit roots, random walks and the sources of business cycles: a survey." Revista Brasileira de Economia, forthcoming.

Cuddington, J.T. \& Urzúa, C.M. 1989. "Trends and cycles in Colombia's real GDP and fiscal deficit." Journal of Development Economics 30: 325-343.

Cuddington, J.T. \& Winters, L.A. 1987. "The Beveridge-Nelson decomposition of time series: a quick computational method." Journal of Monetary Economics 19: 125-127.

Dickey, D.A. \& Fuller, W.A. 1979. "Distribution of the estimators for autoregressive time series with a unit root." Journal of the American Statistical Association 74:427-431.

Fuller, W.A. 1976. Introduction to Statistical Time Series. New York: Wiley. 
Haddad, C. 1977. "Crescimento do produto real brasileiro: 1900/ 1947." In Versiani, F.R. \& Barros, J.R.M., org., Formação Econômica do Brasil. São Paulo: Saraiva.

Hall, R. 1978. "Stochastic implications of the life cycle-permanent income hypothesis: theory and evidence." Journal of Political Economy 86: 971-988.

Harvey, A.C. 1985. "Trends and cycles in macroeconomic time series." Journal of Business and Economic Statistics 3:216-227.

Hurvich, C.M. \& Tsai, C.L. 1989. "Regression and timeseries model selection in small samples." Biometrika 76:297-307.

1991. "Bias of the corrected AIC criterion for underfitted regression and time series models." Biometrika 78: 499-509.

Kooperberg, C. \& Stone, C.J 1991. "A study of logspline density estimation." Computational Statistics and Data Analysis 12: 327-347.

1992. "Logspline density estimation for censored data." Working Paper n으 . 226, Department of Statistics, University of Washington.

Lippi, M. \& Reichlin, L. 1992. "On persistence of shocks to economic variables: a common misconception." Journal of Monetary Economic 29:87-93.

Lucas, R.E. 1987. Models of Business Cycles. Oxford: Basil Blackwell.

McCallum, B.T. 1989. "Real business cycle models." In Barro, R.J., org., Modern Business Cycle Theory. Cambridge: Harvard University Press.

McLeod, A.I. \& Li, W.K. 1983. "Diagnostic checking ARMA time series models using squared-residual autocorrelations." Journal of Time Series Analysis 4:269-273.

Miller, S.M. 1988. "The Beveridge-Nelson decomposition of economic time series: another economical computation method." Journal of Monetary Economics 21:141-142.

Nelson., C.R. 1987. "Spurious trend and cycle in the state space decomposition of a time series with a unit root." Technical Working Paper no . 63, National Bureau of Economic Research. 
Nelson, C.R. \& Kang, H. 1981. "Spurious periodicity in inappropriately detrended time series." Econometrica 49:741-751. 1984. "Trends and random walks in macroeconomic time series: some evidence and implications." Journal of Business and Economic Statistics 2:73-82.

Nelson, C.R. \& Plosser, C.I. 1982. "Trends and random walks in macroeconomic time series: some evidence and implications." Journal of Monetary Economics 10:139-169.

Newbold, P. 1990. "Precise and efficient computation of the Beveridge-Nelson decomposition of economic time series." Journal of Monetary Economics 26: 453-457.

1991. "Structural decomposition of time series with implications in economics, accounting, and finance research." Review of Quantitative Finance and Accounting 1:259-279.

Perron, P. 1988. "Trends and random walks in macroeconomic time series: further evidence from a new approach." Journal of Economic Dynamics and Control 12:297-332.

1989. "The Great Crash, the oil shock and the unit root hypothesis." Econometrica 57:1361-1401.

Phillips, P.C.B. 1987. "Time series regression with unit roots." Econometrica 55:277-302.

Phillips, P.C.B. \& Perron, P. 1988. "Testing for a unit root in time series regression." Biometrika 75:333-345.

Plosser, C.I. 1989. "Understanding real business cycles." Journal of Economic Perspectives 3:51-77.

Said, S.E. \& Dickey, D.A. 1984. "Testing for unit roots in autoregressive-moving average models of unknown order." Biometrika 71: 599-607.

Shapiro, M.D. \& Watson, M.W. 1988. "Sources of business cycles fluctuations." NBER Macroeconomics Annual, 111-148. 